\title{
The Impact of Enterprise Resource Planning (ERP) System Implementation on Organization: Case Study ERP Implementation in Indonesia
}

\author{
Gede Rasben Dantes ${ }^{1}$ and Zainal Arifin Hasibuan ${ }^{2}$ \\ ${ }^{1}$ Department of Information Management, Ganesha University, Singaraja, Bali, Indonesia \\ ${ }^{2}$ Faculty of Computer Science, University of Indonesia, Depok, Jawa Barat, Indonesia
}

\begin{abstract}
Enterprise Resource Planning (ERP) is one of the most popular software technologies for supporting operational organization. It emphasizes business transformation which will lead to process change in its effort to maximize the company's benefit. However, implementation of ERP system does not always give a strategic benefit for the company. Most companies did not succeed in implementing this system. In this study, we focused on the exploration of strategical and tactical impact induced by the implementation of ERP and to find out the correlation among ERP implementation success with the strategical and tactical impact. Thirty-five respondents from seven companies became the samples that represent four different industrial sectors (oil \& service, manufacturing, telecommunication, automotive). It was found that ERP implementation gave more impact to tactical level than to strategical level. This is derived from data analysis using Spearman rank test which shows that $\rho_{\mathrm{yx} 1}=0.167$ (not significant with $\mathrm{p}<0.05$ ) and $\rho_{\mathrm{yx} 2}=0.813$ (significant with $\mathrm{p}<0.01$ ). Thus, specifically for Indonesian companies, the present study shows that ERP implementation acted only as a support toward the core business instead of creating a competitive advantage. The reasons behind these findings are: (1) the companies were not ready to make big investment for implementing all modules in ERP, including the specific modules; (2) the companies were afraid to fail in their implementation, so they chose to implement the modules only for supporting the core business; (3) the ERP implementations were not driven by the organizations' business needs, but by the technology itself; (4) there were other external factors which forced the companies to implement ERP, such as: government policy, bank policy and political issue.
\end{abstract}

Keywords: ERP Implementation, Strategical Impact, Tactical Impact, Competitive Advantage

\section{Introduction}

ERP system is a combination of advanced technologies and best business practices. It enables an organization to achieve its specific business goals and gain a competitive advantage by providing a common platform to integrate all aspects of the business (Xu and Yeh, 2009). Although the failure rate of these ERP implementation has been highly publicized, many companies are not reluctant to invest large sum of money on ERP system, since it is acknowledged that the failures are not caused by the incorrect coding of ERP.

A company needs a big investment for adopting this system to gain a benefit for organization while implementing an ERP system requires a thorough strategic thinking that allows companies to gain better understanding of their business

Copyright (C) 2011 Gede Rasben Dantes and Zainal Arifin Hasibuan. This is an open access article distributed under the Creative Commons Attribution License unported 3.0, which permits unrestricted use, distribution, and reproduction in any medium, provided that original work is properly cited. Contact author: Gede Rasben Dantes e-maill: rasben_dantes@yahoo.com 
processes. ERP system is a software package that needs to be customized in order to meet with business need. We do not need to do the development (coding) as a normal information system. When we do the adoption of technology, we have to consider the change that will happen to the organization, such as: process change, technology change or even organization's structure change, etc. One of these changes relates with the way the company does business; how the business processes are affected by the system.

Every technology adoption will have an impact on the organization, both strategical and tactical impacts. This study focuses on the exploration of strategical and tactical impacts on ERP implementation. The correlation among ERP implementation, strategical impact and tactical impact will also be identified using Spearman rank test (non-parametric). As a preliminary study, thirty-five respondents from seven companies were chosen as the object of the study, covering four different industrial sectors, namely: telecommunication, manufacturing, automotive and oil \& gas companies. The result of the study can be used by the organization to create a competitive advantage through ERP implementation. The findings are also expected to improve knowledge in Enterprise System, Management Information System and impact of ERP implementation on strategic and tactical levels.

\section{Literature Reviews}

The following section reviews a number of studies concerning evaluation of ERP implementation, competitive advantage and impact on ERP implementation.

\section{Evaluation of ERP Implementation}

Successful ERP implementation has been influenced by ERP implementation approach and the Organization Maturity Level (Dantes \& Hasibuan, 2010). Technology is only one aspect in ERP implementation other than people and process that have to be considered. ERP system will have high possibility of success, when the organization does the minimum change on organization's business process and software (O'Leary, 2000). However, this approach will make ERP system as a supporting operational on organization rather than creating a competitive advantage.

Many companies were not successful when implementing ERP system. It was not caused by implementation approach but because the organizational culture was not ready to adopt this system. However, we have to know that business process and organizational culture are two different things. We can use the business process to drive a good organizational culture. Therefore, it is too difficult to conclude that unsuccessful ERP implementation is caused by culture difference between ERP's business process and organization's business process. Other than process and culture, people (employee) have a significant influence on the success of ERP implementation. Employee has to involve on ERP implementation process and also accept the changes that occur.

Various factors may influence the ERP implementation success, such as: organization maturity level, implementation approach, organizational culture, organization's business process, top management commitment and other external factors. A number of studies have been conducted to find the key factors of ERP implementation success (Tsai et.al., 2005; Nah et.al., 2001; Somers and Nelson, 2004; Gargeya and Brady, 2005; Ehie and Madsen, 2005, Bhatti, 2005; Chung et.al., 2008) while some other studies had also tried to evaluate it (Motwani et.al., 2005; Brown and Vessey, 1999; Dantes, 2006; Carton and Adam, 2003; Barki et.al., 2005; Gunson and de Blasis, 2002).

Focusing on this study, four indicators were used to measure the ERP implementation success, namely: budget, time, performance and benefit. In Indonesia, it found that most of ERP implementations are over budget, over time, under performance and benefit does not meet expectation. Judging whether an ERP implementation is successful or not 
depends on the perspective in reviewing the project (Markus, et.al., 1999). An ERP consultant will find an ERP implementation successful when the project can meet the deadline within the allocated budget and the implementation meets the requirements. But a project owner will consider the implementation successful from the benefit gained by the company; whether the implementation supports the company's business strategies. The project owner will also consider the system's performance as one of the points to judge the success of an ERP implementation. In this study, the success of implementation is viewed from the project owner's point of view.

\section{ERP Implementation \& Competitive Advantage}

Changes in technology are important if they can give benefit to the competitive advantage or the industrial structure of the company. Many but not every change in technology will benefit the company. Many changes in technology may worsen the company's competitive position. Even high technology cannot ensure that it will help company to raise its profit. ERP is a high technology which will not give optimum benefit if the approach is not suitable. ERP will give benefit to the company if maximum process change is conducted along its implementation. This process will be followed by maximum software change to make adjustment with the process change.

An optimum process and software change in an implementation is very risky for a company. But if the company is successful in the implementation, it will be the prime mover in technology and it will give positive impact to the competitive position.

It would be ridiculous to say that ERP can not give competitive advantage to the company. However competitive advantage of a company is affected more by the company's business strategy rather than the technology it adopts. How relevant a company's strategy to the technology it adopts will determine the competitive value of the company. But, most companies implement only the standard modules in their ERP implementation. Standard modules among others are: MM (Material Management), PP (Production Planning), SD (Sales \& Distribution), FICO (Finance \& Controlling), and HR (Human Resources) hardly create competitive advantage. These modules only support the company's operational in order to elevate the productivity and lower the operational cost (figure 1). ERP is a generic system. It can be applied by a certain company as well as its competitors. Almost none of the companies implementing ERP in Indonesia implements specific modules which will give competitive advantage. 


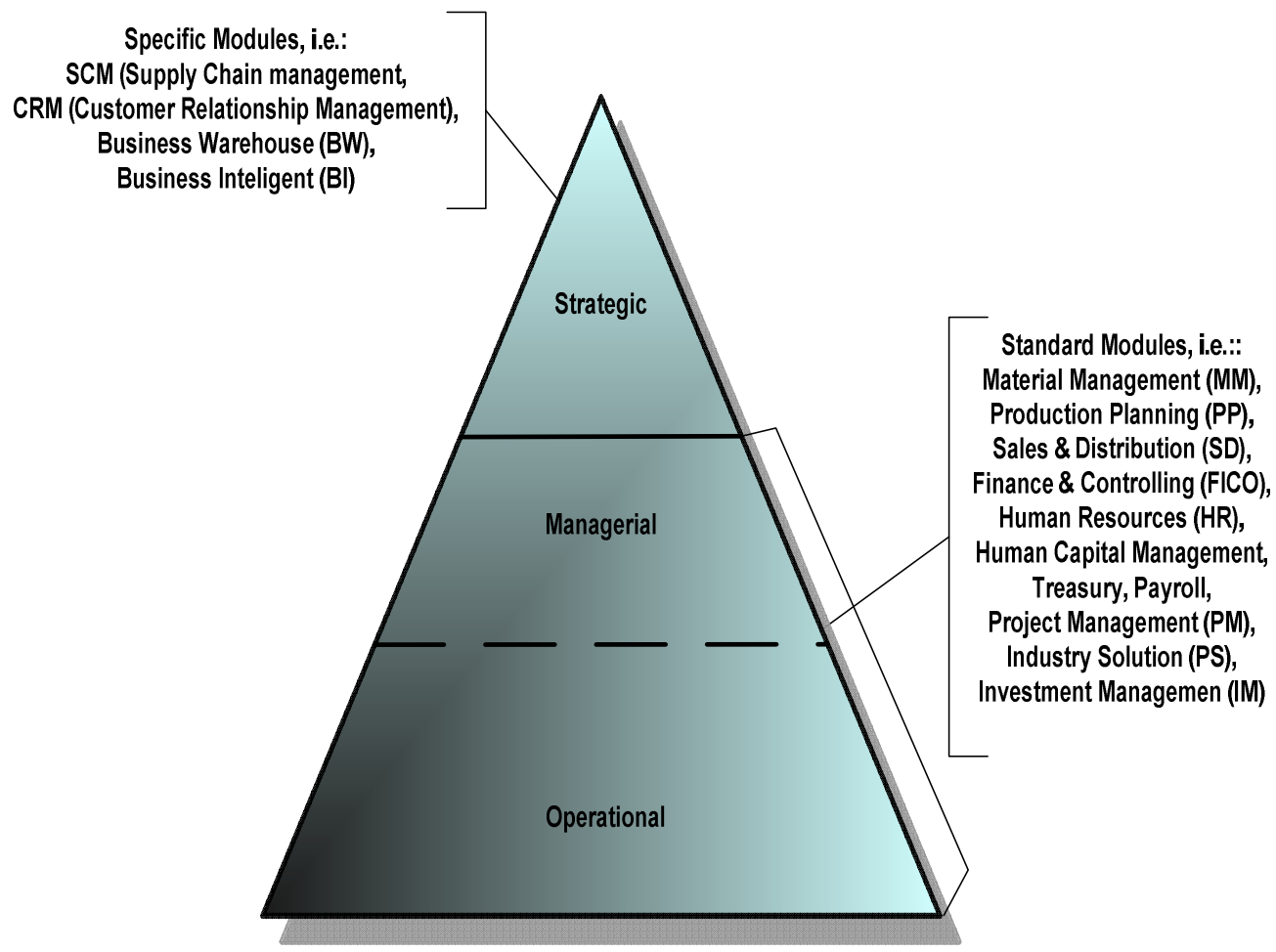

Fig 1. ERP Modules and Organization Hierarchy

\section{Impact of ERP Implementation}

The impact of ERP on a company can be tangible or intangible. Most researches on ERP implementation have focused on the tangible impacts since intangible impacts are more difficult to quantify. According to DeLone \& McLean (1992; 2003), there are three kinds of impacts of ERP implementation, individual, workgroup and organizational impacts. Each impact has its own indicators. These indicators can be used to measure the overall impact of an ERP implementation. In their research, these individual, workgroup and organizational impacts act as one of the variables for measuring the success of ERP implementation while the other variables are information, system and service quality.

Their study has become one of the main references for measuring the success of ERP implementation (Ifinendo, 2006; Wei \& Long, 2009; Palmius, 2007; Gable et.al, 2003). In this research the impacts of ERP implementation are classified into two groups, namely strategical and tactical impacts.
Based on organizational hierarchy, there are three levels in an organization, namely strategic, managerial and operational level. Strategical impacts will affect the strategic level in the sense that ERP implementation will give strategic impacts to the company. These strategic impacts can manifest in the form of innovative business growth; growth business alliance with other organization. They also create competitive advantage, product differentiation, product leading, and other strategic things that affect the external affairs of the organization instead of its internal affairs.

On the other hand, tactical impact will affect the managerial and operational level. If mapped into McFarlan's Matrix, tactical impact will affect more on the key operational and support quadrants (Ward \& Peppard, 2003). The impacts only affect the internal affairs of the organization, such as reduction of operational cost and product cost, increase in productivity, operational efficiency, good time and resource management, human resource development, etc. 


\section{Research Methodology}

The key objective of this study is to examine a number of issues regarding the strategical and tactical impacts on ERP implementation.

The strategical impact $\left(\mathrm{X}_{1}\right)$ is the score of the impact of ERP implementation at strategic level (competitive advantage) in organization. The strategical impact includes some indicators as explained above. However, tactical impact $\left(\mathrm{X}_{2}\right)$ is the score of the impact of ERP implementation at tactical (operational and managerial) level.
The success in ERP implementation is the score for success or lack of success in its implementation in a company. The indicators measured include cost and time of implementation (Iskanius, 2009), performance and benefit obtained. In this study, we classify level of success into four, namely: (1) high success, that if all indicators are met; (2) success, that if only performance and benefit indicators are met; (3) low success, if cost and time indicators are met; and (4) fail, if none of the indicators is met. This success of implementation is taken from the organization point of view, in which the organization is the project owner. The constellations of the variables above are illustrated in figure 2 .

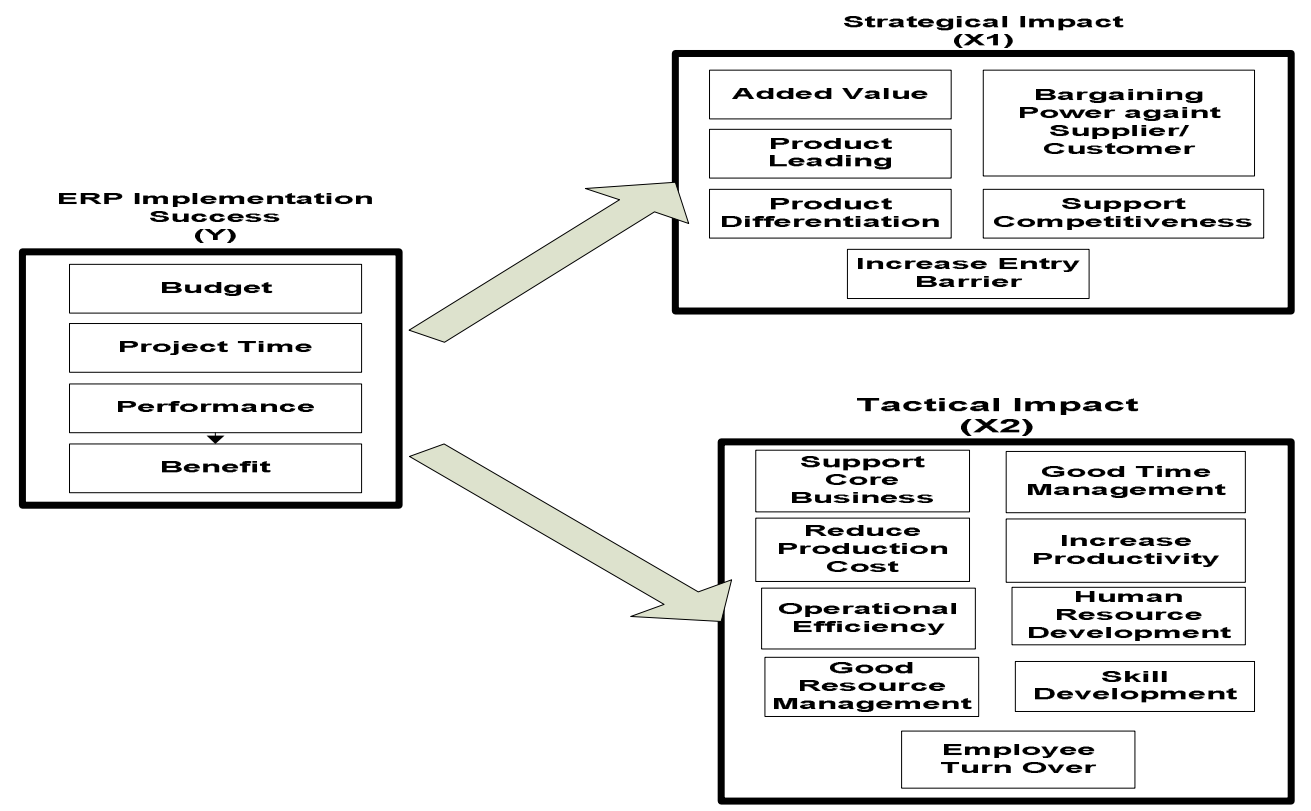

Fig 2. The Hypothetical Model of Impact on ERP Implementation

As a preliminary study, the research covered seven companies which have been implementing ERP system to support their business process. These seven companies include four different industrial sectors, namely: telecommunication, manufacturing, automotive and oil \& gas company.

To address the study objectives, a survey questionnaire was considered the most appropriate research methodology. An ERP system was sent to seven companies that have been implemented at least one year. There are top five companies in their respective industrial sectors. The practical samples were company's management level, ERP consultants, IT staff and users involved in the development and use of ERP system. The survey received 35 responses from 70 questionnaires that are sent to the company as preliminary study. 
Table 1: Research Sample Base on Industrial Sector

\begin{tabular}{|c|l|c|}
\hline No. & \multicolumn{1}{|c|}{ Industrial Sector } & Number of organization \\
\hline 1. & Telecommunication & 2 \\
\hline 2. & Manufacturing & 3 \\
\hline 3. & Automotive & 1 \\
\hline 4. & Oil \& Gas & 1 \\
\hline \multicolumn{2}{|c|}{$\sum$ organization as a sample } & 7 \\
\hline
\end{tabular}

Other than the questionnaire, the present study also conducted interviews and documents observation to support the research data. Interviews were conducted with several ERP consultants at the technical level as well as the functional one, IT Staffs, and with users involved in the ERP implementations in each of the seven companies. The interviews were conducted in structured and unstructured methods. The questions posed focused on: (1) the holistic of ERP implementation, (2) the impact of ERP implementation that can be classified into strategical and tactical impact, (3) the benefits or competitive advantages gained.

\section{Discussion \& Result}

This section discusses the impacts of ERP implementation in Indonesia, namely: strategical and tactical impacts. The strategical impact includes added value, product leading, product differentiation, entry barrier increase, bargaining power against supplier/customer and competitiveness support. However, the tactical impact includes supporting core business, reducing product cost, operational efficiency, good resource management, good time management, people resistance, increasing productivity, human resource development, skill development and restructurisation.

\section{Strategical Impact on ERP Implementation}

The following findings are the outcome of the surveys conducted in the seven Indonesian companies which have been implementing ERP. The following table exposes the survey results concerning the three variables involved in this study: ERP implementation success, strategical impact and tactical impact.
The strategical impact which is focused on in this study contains added value, product leading, product differentiation, entry barrier increase, bargaining power against supplier/customer and competitiveness support. Refering to our survey, it is found that: $83.33 \%$ respondents agree that ERP implementation can create an added value for the organization; $5.56 \%$ agree that ERP system can make their products leading on the market; $5.56 \%$ agree that ERP system can make a product differentiation compared to others competitor; $16.67 \%$ agree that ERP system can increase entry barrier; $22.22 \%$ agree that ERP system can increase bargaining power against supplier/customer; and 50\% respondents agree that ERP system can support competitiveness of organization (see fig. 3).

The findings show that ERP implementation in Indonesia have more significant impact on tactical, instead of strategical. Data analysis conducted using Spearman rank test (non-parametric) show that correlation between ERP implementation and strategical impact, $\rho_{\mathrm{yx} 1}=0.167$ (not significant with $\mathrm{p}<0.05$ ). While the correlation between ERP implementation and tactical impact, $\rho_{\mathrm{yx} 1}=$ 0.813 (significant with $\mathrm{p}<0.01$ ) (see table $2)$. It reflects that most of Indonesian companies only implement the standard module of ERP which only supports core business. On the other hand, the company did not do an optimal business process improvement before they implement ERP system (Dantes \& Hasibuan, 2010). ERP system implementation has been driven by technology itself rather than an organization's business need. That is the most reason why the ERP implementation in Indonesia is only an impact on tactical level. Gaining competitive advantage is the most reason why the company is adopting 
ERP system. But most of ERP implementations in Indonesia cannot create a competitive advantage for the companies. Therefore, it needs to do business process reengineering and software change in order to meet an organization's business need. However, this approach has a risk of being unsuccessful to the ERP implementation (O'Leary, 2000). Other than that, the company also needs to implement some modules that support organization's strategic level (i.e. business information warehouse (BW), business intelligence (BI), Supply Chain Management (SCM), Customer Relationship Management (CRM), etc).

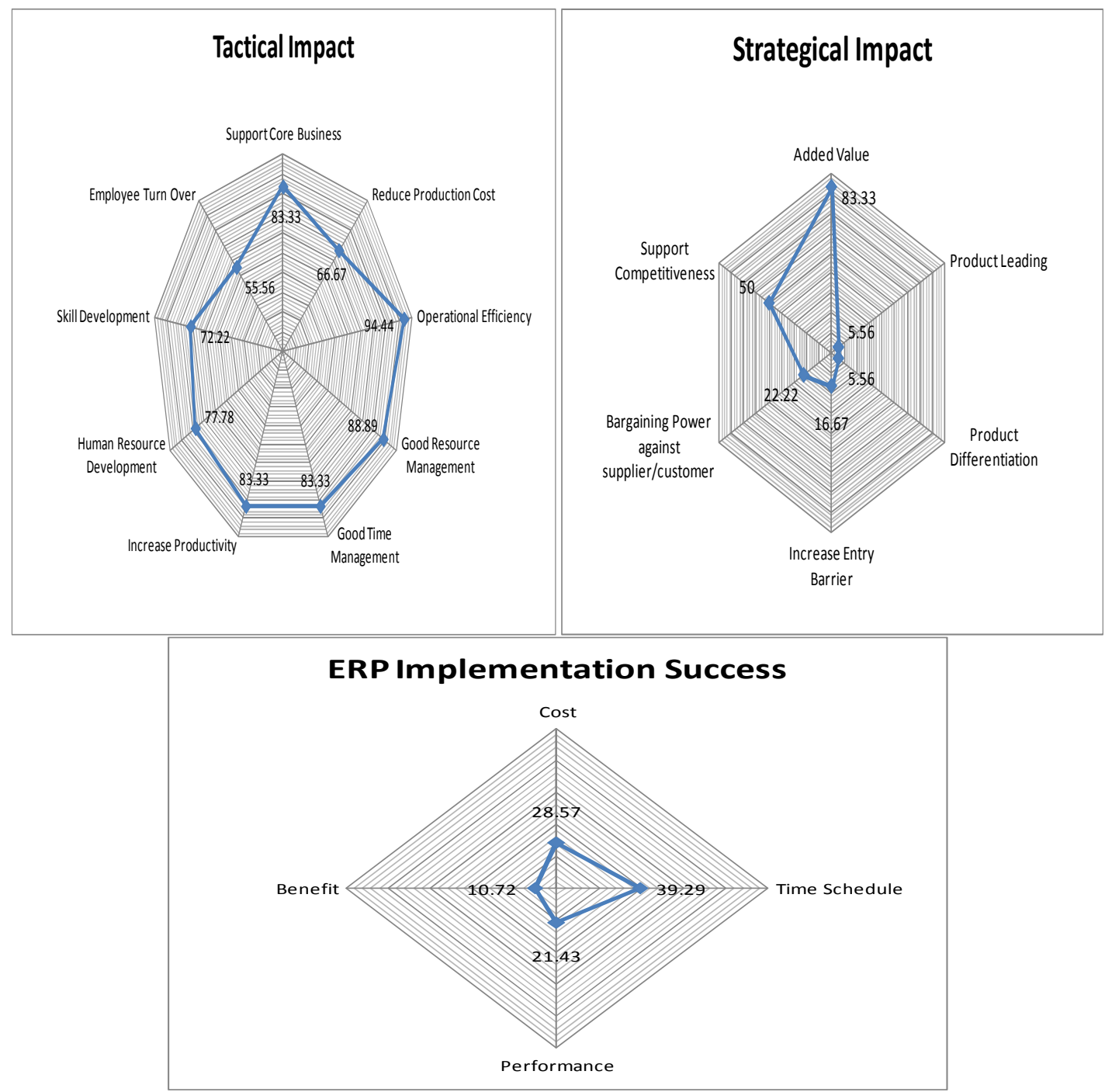

Fig 3. Survey Result

Strategical \& Tactical Impact on ERP Implementation

The implementation of specific modules in ERP system is expected to be aligned with the company's business strategy, so it can give strategic benefit and sustain future business. Other than implementing specific modules, Business Process Reengineering (BPR) is also needed to optimize the current business process in order to gain competitive advantage (Hammer \& Champy, 1993; Davenport, 2000; Somer \& Nelson, 2003). BPR is rarely taken by Indonesian companies, especially government-owned ones. It is suspected that BPR will create radical changes which 
will lead to the reduction of employees. Further, BPR will also change the company's business processes which have been the path of the company for years. Employees will have to learn completely new things and this will lead to the declining in the overall productivity. Those are the reasons why Indonesian companies are frightened in implementing BPR before implementing ERP.

According to O'Leary (2000), ERP implementation approach (BPR drives ERP) is very risky. But if a company is successful in implementing it, the company will gain optimum benefit as well as competitive advantage. The other approach that is often adapted is ERP drives BPR. This approach adopts the whole business process provided by ERP. This approach has minimum risks (O'Leary, 2000). However, this ERP system will only support the company's operational or it will only give impact to the managerial and operational (tactical) level.

\section{Tactical Impact on ERP Implementation}

Other than the strategic impacts discussed above, ERP implementation also gives tactical impacts. These include managerial and operational level in the organizational hierarchy. As mentioned before, ERP implementation gives more significant impact tactically than strategically, with $\rho_{\mathrm{yx} 1}=0.813$ (significant with $\mathrm{p}<0.01$ ) (see table 2). The indicators used for measuring tactical impact in this research core business support, production cost reduction, operational efficiency, good resource management, good time management, productivity increase, human resource development, skill development and employee turnover.

Based on this study, we found that $83.33 \%$ respondents agree that ERP system can support core business; $66.67 \%$ agree that it can reduce production cost; $99.94 \%$ agree that it can make an operational efficiency; $88.89 \%$ agree that it can make a good resource management; $83.33 \%$ agree that it can make a good time management; $83.33 \%$ agree that it can increase productivity; $77.78 \%$ agree that it can improve human resource development; $72.22 \%$ agree that it can improve skill development; and $55.56 \%$ agree that it can cause employee turnover (see fig. 3 ).

This indicates that ERP implementation is used only to improve the organization's internal process instead of gaining strategic benefit while in fact ERP offers more than just that. ERP can promote business alliance and business innovation, and it can create product differentiation and product leading. The reasons behind these findings are (1) the companies are not ready to make big investment for implementing all modules in ERP, including the specific modules; (2) the companies are afraid to fail in their implementation, so they choose to implement the modules for supporting the core business only; (3) the ERP implementations are not driven by the organizations' business needs, but they are driven by the technology itself; (4) there are other external factors which force the companies to implement ERP, such as: government policy, bank policy and political issue.

One interesting thing about ERP implementation in Indonesia is the high rate of the employee turnover. With the increasing skill owned by the employees, both from the functional and the technical, employees are motivated to find new employments which give better rewards. This proves that Indonesian companies do not consider the employees' capabilities professionally.The companies stick to seniorities (the number of years the employees have spent with the company) rather than to capabilities of the employees. Thus, the company will undergo both tangible (training costs, productivity, etc) and intangible (i.e. knowledge) loss. The companies are forced to find new employees while it is not certain whether they possess sufficient capabilities in this system. 
Table 2: Spearman Rank Test Matrix of All Variables ( $\mathrm{N}=35$ )

\begin{tabular}{|c|c|c|}
\hline & $\begin{array}{c}\text { Strategical } \\
\text { Impact } \\
\left(\mathbf{X}_{1}\right)\end{array}$ & $\begin{array}{c}\text { Tactical Impact } \\
\left(\mathbf{X}_{2}\right)\end{array}$ \\
\hline $\begin{array}{c}\text { ERP Implementation } \\
\text { Success } \\
(Y)\end{array}$ & $0.167^{* *}$ & $0.813^{*}$ \\
\hline
\end{tabular}

${ }^{*}$ Significant correlation with $\mathrm{p}<0.01$

** Not Significant correlation with $\mathrm{p}<0.05$

\section{Conclusion}

ERP can give both strategical and tactical impacts. Strategical impacts will affect strategic things in the company as well as the company's future business. Tactical impacts will affect the internal affairs of the organization, both on the managerial and operational level. The study found out that ERP implementation in Indonesia gives more significant tactical impact rather than strategical impact. By analyzing the data using Spearman rank test, it is found that the correlation between ERP implementation success and strategical impact $\left(\rho_{\mathrm{yx} 1}\right)=0.167$ (not significant with $\mathrm{p}<0.05$ ), while the correlation between ERP implementation success and tactical impact is $\rho_{\mathrm{yx} 1}=0.813$ (significant with $\mathrm{p}<0.01$ ). This shows that ERP implementation in Indonesia acts only as a support and a key operational instead of a means of gaining competitive advantage and future business.

The present study is expected to give holistic view of the impacts of ERP implementation both strategically and tactically in order to motivate the companies to gain strategic as well as tactical impact in their ERP implementation. Strategic impacts can be gained by applying specific modules like BW, BI, SCM, CRM, etc, and by doing BPR before implementing ERP. The findings are also expected to improve knowledge in Enterprise System, especially impact on ERP implementation and Management Information System

\section{Future Research}

In line with the findings of the present study which discovers that ERP implementation in Indonesia gives more impact on tactical rather than strategic, further research needs to be conducted in order to develop a model in ERP implementation so it can give significant strategical impact to a company.

\section{References}

Barki, H., Oktamis, S. \& Pinsonneault, A. (2005). "Dimensions of ERP Implementations and Their Impact on ERP Project Outcomes," Journal of Information Technology Management, XVI(1).

Bhatti, T. R. (2005). "Critical Success Factors for The Implementation of Enterprise Resource Planning (ERP): Empirical Validation," The Second International Conference on Innovation in Information Technology (IIT).

Brown, C. \& Vessey, I. (1999). "Managing the Next Wave of Enterprise Systems: Leveraging Lessons from ERP," MIS Quarterly Executive.

Carton, F. \& Adam, F. (2003). "Analysing the Impact of Enterprise Resource Planning Systems Roll-outs in Multi-National Companies," Electronic Journal of Information Systems Evaluation, 6(2). 2132.

Chung, B. Y., Skibniewski, M. J., Lucas, H. C. \& Kwak, Y. H. (2008). “Analyzing Enterprise Resource Planning System Implementation Success Factors in the Engineering Construction Industry," Journal of Computing in Civil Engineering, 373 - 382.

Dantes, G. R. (2006). 'ERP Implementation and Its Impact for Human \& Organizational Cost,' M.S. Thesis, University of Indonesia, Jakarta, Indonesia. 
Dantes, G. R. \& Zainal, A. H. (2010). 'The Relationship of Organization Maturity Level and Enterprise Resource Planning (ERP) Adoption (Case Study: ERP Implementation in Indonesian Companies),' Proceedings of the 14th International Business Information Management Association Conference, June 23-24, 2009, Istanbul, Turkey, ISBN: 978-09821489-3-8, 2444-2456.

Davenport, T. H. (2000). Mission Critical: Realizing The Promise of Enterprise Systems, Boston, Massachusetts, Harvard Business School Press.

DeLone, W. H. \& McLean, E. R. (1992). "Information Systems Success: The Quest for The Dependable Variable," Information Systems Research, 3(1). 60-95.

DeLone, W. H. \& McLean, E. R. (2003). "The DeLone and McLean Model of Information Systems Success: A Ten-Year Update," Journal of Management Information Systems, 19(4). 9-30.

Ehie, I. C. \& Madsen, M. (2005). "Identifying Critical Issues in Enterprise Resource Planning (ERP) Implementation," Computers in Industry, 56, 545-557.

Gable, G. G., Sedera, D. \& Chan, T. (2003). "Enterprise Systems Success: a Measurement Model," Proceedings International Conference on Information Systems (ICIS). Seattle, WA.

Gargeya, V. B. \& Brady, C. (2005). "Success and Failure Factor of Adopting SAP in ERP System Implementation," Business Process Management Journal, 11(5). 501-516.

Gunson, J. \& de Blasis, J. P. (2002). "Implementing ERP in Multinational Companies: Their Effect on the Organization and Individuals at Work," Journal ICT.

Hammer, M. \& Champy, J. (1993). "Reengineering the Corporation: A Manifesto for Business Revolution," Harper Business, New York.

Ifinedo, P. (2006). "Extending the Gable et al. Enterprise Systems Success
Measurement Model: a Preliminary Study," Journal of Information Technology Management, 17(1). 14-33.

Iskanius, P. (2009). "The ERP Project Risk Assesment - A Case Study," World Congress on Engineering, London, UK.

Markus, M. L. \& Tanis, C. (1999). "The Enterprise System Experience - From Adoption to Success," Framing the Domains of IT Research: Glimpsing the Future Through the Past, chapter 10. Pinnaflex Educational Resources.

Motwani, J., Akbul, A. Y. \& Nidumolu, V. (2005). "Successful Implementation of ERP Systems: A Case Study of an International Automotive Manufacturer," International Journal of Automotive Technology and Management, 5(4). 375-386.

Nah F. F.-H.,Lau, J. L.-S. \& Kuang, J. (2001). "Critical Factors for Successfull Implementation of Enterprise Systems," Business Process Management, 7(3). 285296.

O'Leary, D. E. (2000). Enterprise Resource Planning Systems (Systems, Life Cycle, Electronic Commerce, and Risk). Cambridge University Press, Cambridge.

Somers, T. M. \& Nelson, K. G. (2004). "A Taxonomy of Players and Activities Across the ERP Project Life Cycle," Information and Management.

Tsai, W., Chien, S., Hsu, P. \& Leu, J. (2005). "Identification of Critical Failure Factors in the Implementation of Enterprise Resource Planning (ERP) System in Taiwan's Industries," International Journal of Management and Enterprise Development.

Ward, J. L. \& Peppard, J. (2002). Strategic Planning for Information Systems, 3rd Edition, John Wiley \& Sons, Chicester.

Xu, Y. \& Yeh, C.-H. (2009). "Evaluating Critical Strategies for Enterprise Resource Planning System Implementation," Second Internatonal Symposium on Electronic Commerce and Security. 